\title{
Drug resistance to molecular targeted therapy and its consequences for treatment decisions in non-small-cell lung cancer
}

\author{
Johanna N. Spaans ${ }^{1}$ and Glenwood D. Goss ${ }^{1,2,3}$ * \\ 1 Ottawa Hospital Research Institute, Ottawa, ON, Canada \\ ${ }^{2}$ Ottawa Hospital Cancer Centre, Ottawa, ON, Canada \\ ${ }^{3}$ Department of Medicine, University of Ottawa, Ottawa, ON, Canada
}

\section{Edited by:}

Vera Hirsh, McGill University Health Centre, Canada

Reviewed by:

Gregory Masters, Medical Oncology Hematology Consultants, PA, USA

Janaki Deepak, University of

Maryland School of Medicine, USA

*Correspondence:

Glenwood D. Goss, 501 Smyth Road, Ottawa, ON K1H 8L6, Canada

e-mail:ggoss@toh.on.ca
Our ability to detect and directly target the oncogenic alterations responsible for tumor proliferation has contributed significantly to the management of lung cancer in the last decade. The therapeutic efficacy of molecularly targeted therapy is, however, mainly limited to patients harboring certain genetic mutations and is generally short-lived. Herein, we review primary and secondary drug resistance using the most well-studied of the molecularly targeted agents, the tyrosine kinase inhibitors targeting the epidermal growth factor (EGF) receptor, and the anaplastic lymphoma kinase (ALK) rearrangement, the current limitations of targeted therapies and their consequences on the management of patients with lung cancer.

Keywords: EGFR, inhibition, primary resistance, acquired resistance, molecular biology
The treatment of advanced non-small-cell lung cancer (NSCLC) had reached a therapeutic plateau prior to the introduction of molecularly targeted agents (MTAs), with a median survival of 8-12 months $(1,2)$. With an improved understanding of the molecular biology of lung cancer, enabled by advances in highthroughput technology, have come molecular therapies that target specific receptors and oncogenic pathways responsible for tumor growth and proliferation. Despite the demonstrated superiority of these MTAs over standard chemotherapy in subgroups of patients $(3,4)$, their therapeutic efficacy is limited to patients harboring the targeted genetic aberration and is generally short-lived. Any future advances in the survival of patients with advanced NSCLC will hinge on our ability to expand on the percentage of patients eligible and responsive to targeted therapy and our capacity to mitigate the mechanisms of acquired resistance that prevent long-term disease control.

As the most well-studied of the MTAs, tyrosine kinase inhibitors in NSCLC targeting the epidermal growth factor (EGF) receptor (erlotonib, gefitinib, and afatinib) and the anaplastic lymphoma kinase (ALK) rearrangement (crizotinib) provide a useful framework in which to understand the current limitations of molecularly targeted therapy and their consequences in the management of patients with NSCLC.

\section{PRIMARY RESISTANCE TO EGFR INHIBITORS}

The EGFR pathway is known to be active in NSCLC (5) and protein overexpression is known to be associated with poorer prognosis (6). Early on in the clinical development of EGFR-tyrosine kinase inhibitors (EGFR-TKIs), which targeted this pathway, it was realized that patients whose tumor harbored an activating mutation in the EGFR gene at exons 19 and 21 had more dramatic responses and better clinical outcomes than their EGFR wild-type (W/T) counterparts $(7,8)$. This has resulted in some countries limiting regulatory approval in the first-line setting to patients whose tumors harbor these sensitizing mutations (9). Although common among lung cancer patients of Asian descent (10), sensitizing EGFR mutations are relatively uncommon in North American and European NSCLC populations with a prevalence of $\sim 15 \%$ in patients with advanced non-squamous histology (11). Further, despite their heightened sensitivity to EGFR-TKIs, as many as one third of NSCLC patients with tumors with sensitizing EGFR mutations do not respond to targeted therapy $(12,13)$.

The mechanisms of primary resistance to EGFR-TKIs are best considered in terms of patients with tumors with (EGFR mutant) and without (EGFR W/T) sensitizing mutations. In the latter case, patients may not respond to EGFR-TKIs because their tumors are being driven by other oncogenic pathways that are not sensitive to EGFR inhibition. Indeed, different oncogenic alterations have been identified in up to half of patients with EGFR W/T disease (14). Importantly, the successful targeting of one such alteration, namely the ALK gene rearrangement with crizotinib (15) demonstrates the feasibility of addressing this form of primary resistance in the EGFR W/T population. Therapies targeting other mutations that commonly occur among EGFR W/T patients such as c-ros oncogene 1 (ROS1), ret proto-oncogene (RET), v-raf murine sarcoma viral oncogene homolog B (BRAF), and the human EGF 2 (HER2) are currently under development.

In addition, primary resistance in the EGFR W/T population may be the result of activation of alternate parallel signaling pathways, which can overcome EGFR blockade, that are independent of a pathway-specific activating mutation. Activation of the insulinlike growth factor receptor (IGFR) pathway (16) is one such potential mechanisms of primary resistance. Blockade of these alternate pathways to enhance EGFR TKI efficacy is a strategy that is being investigated, but to date has yielded mixed results (17-19). Lack of response to EGFR-TKIs among patients with 
W/T tumors may also be due to incomplete binding of the drug to the EGF receptor or because of insufficient drug concentration necessary for effective pathway blockade (20). Further, as only one of four receptor tyrosine kinases in the $\operatorname{ERbB}$ family $(21,22)$, the isolated targeting of the EGF/Erb1 receptor may not prevent autophosphorylation and downstream pathway activation by the other receptors (i.e., Erb2, Erb3, Erb4). Newer second-generation irreversible pan-HER tyrosine kinase inhibitors such as dacomitinib and afatinib that target multiple receptors are being evaluated in both EGFR W/T and EGFR-mutant populations as a strategy to enhance and prolong treatment response $(23,24)$.

In patients with tumors with EGFR sensitizing mutations a number of factors have been identified in the primary resistance setting, which may modulate or blunt the therapeutic efficacy of EGFR-TKIs. While most oncogenic driver mutations are mutually exclusive in context of lung cancer, the co-existence of EGFR mutations with other oncogenic alterations, including class A phosphoinositide 3-kinase (PI3KCA), have been reported (25). Activation of compensatory signaling pathways by these other mutations may afford continued disease progression and negate or circumvent clinical benefit derived from EGFR TKIs in patients whose tumors harbor EGFR mutations. The dual targeting of co-existing mutations with combination therapy in EGFR-mutant disease is currently under investigation (clinical trials.gov: NCT01570296).

In a similar fashion, exogenous factors, including MED12mediated transforming growth factor beta (TGF- $\beta$ ) activation (26) and hepatocyte growth factor (HGF) ligand overexpression (27), may enable the activation of alternate signaling pathways in tumors that may override the pathways inhibited by the EGFR-TKIs. The inhibition of these compensatory pathways in tumors with EGFR sensitizing mutations is a hot topic in clinical research with the testing of a number of combination therapies that include agents to overcome TGF- $\beta$ and HGFmediated resistance [e.g., heat shock protein (Hsp) 90 inhibitors] in both the primary (clinicaltrials.gov: NCT01714037) and resistance setting (clinicaltrials.gov: NCT01259089, NCT01288430, NCT01851096).

Finally, exogenous apoptotic factors have been identified that may modulate the impact of EGFR TKIs in patients with tumors with sensitizing EGFR mutations and may explain their variable treatment response. Increasing evidence suggests that expression levels of proapototic BH-3 only molecule (BIM) can influence treatment-induced apoptosis $(28,29)$ and further that pretreatment BIM expression may play a role in treatment response to many kinase inhibitors across many disease sites $(30,31)$. While in lung cancer, it has been shown that low pre-treatment BIM levels are associated with shorter time to progression (29), available pro-apoptotic assays are not currently being used in clinical practice to predict treatment response. Targeted therapies with B-cell lymphoma 2 (blc2) inhibitors that enhance apoptosis, however, are currently being evaluated in combination with EGFR-TKIs as a strategy to enhance treatment response (clinicaltrials.gov: NCT00988169).

Despite early and dramatic treatment responses in up to two thirds of patients with EGFR sensitizing mutations, most patients will eventually progress while on therapy within a year of treatment initiation (12). Beyond the level of pre-treatment apoptotic factors, such as BIM discussed previously, a number of other factors have been suggested to influence the development of clonal and sub-clonal EGFR-resistant cell populations. Specifically, both factors affecting the drug metabolism and characteristics of the treatment schedules may impact the development of acquired resistance in previously responsive patients (32). While the higher metabolic clearance of EGFR-TKIs among smokers and fast metabolizers has long been recognized as a negative predictor for time to progression (33), only recently have the pharmacokinetics of different dosing schedules been considered for their potential influence on the evolution of drug resistance to EGFR TKIs. Specifically, based on evolutionary modeling and clinical data, it has been proposed that pulsed high dose with continuous low dose EGFR-TKI treatment helps to maintain sensitive cell populations and may extend the therapeutic benefit of EGFR-TKI therapy beyond progression (34). While standard once daily dosing continues to be used in the clinic for approved MTAs, research is on-going to define characteristics of the treatment regimen that may delay disease progression and optimize therapeutic outcomes with EGFR-TKI therapy (clinicaltrials.gov: NCT01967095).

Although criteria for acquired resistance have now been developed (35), resistant disease is best considered along an evolutionary continuum, where resistant clones eventually overrun EGFR-sensitive cells, leading to the clinical characteristics of disease progression. The existence of EGFR-sensitive cells in tumors that progress is supported by reports of clinical response in patients re-challenged with EGFR-TKIs (36) and also by reports of disease flare in up to $15 \%$ of patients who are taken off EGFR-TKI therapy at disease progression (37).

\section{SECONDARY EGFR-TKI RESISTANCE}

Genetic adaptations and altered network signaling pathways invariably lead to drug resistance in patients whose tumors harbor EGFR sensitizing mutations who initially respond to EGFRtargeted therapy (acquired resistance). Molecular profiling of tumors with acquired resistance to EGFR-TKIs has identified a number of resistance mechanisms and dominant acquired resistance phenotypes, which may be useful in guiding future treatment. The most common mechanism of acquired resistance to EGFR-TKI is the development of a second mutation of the EGFR that is resistant to therapy. While a number of secondary mutations have been identified (38), the most common "gatekeeper" mutation is that of the T790M, which occurs in 50-60\% of patients with acquired resistance to EGFR-TKIs (39). This secondary mutation is believed to exert its effect by enhancing ATP kinase affinity, thereby decreasing sensitivity to the ATP-competitive EGFR TKIs (40). Importantly, the development of secondary resistance mutations in the EGFR kinase domain has implications in the re-challenging of patients with previously sensitive disease and has fueled research in the development of second and third generation inhibitors (41-45). Despite encouraging phase II data of one such second-generation inhibitor (dacomitinib) in previously treated patients $(41,42)$, emerging phase III data suggests that there is no overall survival benefit associated with its use in previously treated EGFR W/T patients or those with acquired EGFR-TKI resistance (23). Similarly, while interim analysis of 
another second-generation irreversible ErbB family blocker (Afatinib) in patients with acquired resistance to EGFR-TKIs suggested improved progression-free survival (PFS) (43), the lack to an overall survival benefit observed in this phase $2 \mathrm{~b} / 3$ randomized trial (24) does not support the strategy of extended EGFR blockade in the EGFR-resistant population.

Most recently, the finding of a T790M mutation in tumors at the time of initial diagnosis $(44,45)$ has implicated the mutation in primary EGFR-TKI resistance, suggesting that up-front treatment with second/third generation EGFR-TKIs may confer added benefit over their use in the second-line setting in patients with T790M-mediated acquired resistance. Indeed, preliminary clinical reports of second-generation EGFR inhibitors in the first-line treatment setting support their up-front use in patients whose tumors harbor EGFR mutations $(46,47)$.

An alternate mechanism of secondary resistance is the activation of other signaling pathways by adaptive de novo alterations that develop outside the EGFR kinase domain in response to treatment. A number of these alterations have been identified; the most well-studied being MET amplification, which occurs in 10-20\% of patients with EGFR-TKI resistant disease (48). Other less common mutations include HER2 amplification $(49,50)$, activation of PIK3Ca (51) and BRAF (52), and loss of phosphatase and tensin homolog (PTEN) function (53).

Crosstalk between key signaling pathways may also play a role in the development of acquired resistance to EGFR inhibitors. Specifically, the activity of the angiogenic VEGF pathway has been suggested to play a role in resistance to EGFR-TKIs (54), which is not surprisingly given the common downstream effectors shared by these parallel pathways (55). Although preclinical data across different tumor types $(56,57)$ and early phase lung cancer clinical trials $(58,59)$ pointed to the potential utility of dual inhibition of VEGF and EGFR, phase III data of the dual inhibitor vandetanib suggest that this is not a promising approach to overcome acquired resistance to EGFR-TKIs in advanced NSCLC (60).

Finally, a less common but well documented mechanism of acquired resistance to EGFR-TKIs is histological transformation from NSCLC to SCLC or epithelial-mesenchymal transition (EMT), which has been reported in up to $3 \%$ of EGFRTKI resistant patients (61). Increasing evidence suggest that these transformations are linked to the activation of the AXL kinase, the inhibition of which may restore EGFR-TKI sensitivity in previously resistant cells (62). Collectively, these mechanisms clearly demonstrate the multitude of adaptive strategies developed by the tumor to ensure its continued growth and underscores the complexity of treating EGFR-TKI-resistance disease.

While the above resistant disease phenotypes are useful in the classification of acquired resistance, these adaptive mechanisms may not be mutually exclusive. Indeed, it has recently been proposed that T790M mutations and MET amplifications are complementary and may co-exist in the development of drug resistance (63). In addition, oncogenic driver mutations may be tumor specific, as different driver mutations from different tumor sites within the same individual have been identified in patients with EGFR-TKI resistant disease (39), further illustrating the challenges in managing patients with acquired resistance.

\section{PRIMARY RESISTANCE TO ALK INHIBITORS}

Between 1 and $3 \%$ of patients with advanced NSCLC have tumors that harbor sensitizing chromosomal rearrangements of the ALK gene (64-66). The ALK inhibitor crizotinib has recently been approved for the treatment of patients with ALK-positive tumors, however, as with EGFR-TKIs not all patients respond to therapy. Specifically, while phase III studies have shown that crizotinib improves PFS compared to chemotherapy in previously treated NSCLC patients with ALK-positive disease $(\mathrm{HR}=0.49$ $95 \%$ CI: $0.37-0.64, p<0.001$ ), only $65 \%$ of patients were shown to respond to therapy (67). While primary resistance among patients with ALK-positive tumors is less well-understood, the occurrence of drug-resistant ALK mutations and compensatory mechanisms have been advanced as potential mechanisms of primary resistance (68).

In summary, less than $20 \%$ of patients have tumors with an EGFR or ALK mutation at the time of diagnosis, and of these, only $60-70 \%$ of patients respond to currently available MTAs. Therefore, we are mandated to address the approximately $80 \%$ of patients whose tumors are de novo resistant to EGFR and ALK inhibition, a percentage of whom are resistant due to other oncogenic driver mutations such as Kirsten rat sarcoma viral oncogene homolog (KRAS), BRAF, and RET, among others. Many investigations targeting these mutations are on-going.

\section{SECONDARY RESISTANCE TO ALK INHIBITORS}

While secondary mutations in the ALK domain have been identified in approximately one-third of the patients with acquired resistance to ALK inhibitors (69), unlike acquired resistance to EGFR-TKIs, there does not appear to be a dominant secondary mutation. Further complicating the management of such patients, multiple mutations within the same individual have also been reported in patients with acquired resistance (70). Of note, secondgeneration ALK inhibitors have, however, recently shown high response rates ( $48 \%$ confirmed responses) in patients previously treated with crizotinib, in tumors with and without secondary mutations in ALK (71). These results support the importance of ALK in crizotinib-resistant disease and the continued effort in targeting the ALK domain.

\section{TREATMENT IMPLICATIONS}

Since the publication of the initial reports over a decade ago, we now have a much better understanding of which patients stand to benefit most from targeted therapies with EGFR and ALK tyrosine kinase inhibitors and the intrinsic and adaptive mechanisms that limit treatment response and inevitably lead to acquired drug resistance. Despite these treatment advances, there are currently a limited number of therapeutic options available to patients not harboring sensitizing EGFR mutations or rearrangement of the ALK gene. Further, the mechanisms of acquired resistance among those who initially respond to treatment remain uncharacterized in almost $40 \%$ of patients with acquired resistance (72). That said, many agents targeting other oncogenic mutations are in phase III development, and in the near future will expand the armamentarium of targeted therapies available in the treatment of advanced NSCLC. The following strategies are proposed in the current and future management of patients with NSCLC. 
All patients presenting with advanced NSCLC should be screened for all known oncogenic driver mutations with treatment assigned accordingly based on available molecularly targeted therapies. With the approval of second line and third line (T790M specific) EGFR-TKIs, it may also be useful to screen up-front for T790M mutations and preferentially treat patients harboring these mutations with these second and third generation therapies, given the shorter PFS that patients harboring this mutation experience with first-line reversible EGFR-TKIs (44). In addition, for patients harboring sensitizing EGFR mutations, the assessment of pre-treatment BIM expression may be a useful approach to help to optimize EGFR-TKI treatment outcomes, with the addition of anti-apoptotic inhibitors such as Blc2 to the treatment regimen.

While alternate dosing schedules, such as pulsed high dose with continuous low dose may be shown to delay time to disease progression, current treatment regimens of approved targeted agents are limited to once daily dosing. EGFR-TKI treatment should ideally be continued in the case of disease progression until the initiation of second-line therapy, given the potential for disease flare (37) and data that suggest that patients may benefit from continued treatment beyond progression $(73,74)$. As it has been shown that isolated sites of disease progression may be successfully treated while continuing on EGFR-TKIs (75), the decision to discontinue EGFR-TKI therapy at disease progression should be considered in the context of available therapeutic alternatives and the potential benefit of continued EGFR-TKI therapy. For example, treatment with afatinib in addition to chemotherapy has recently been shown to delay progression over chemotherapy alone (5.6 vs. 2.8 months) in patients who had progressed on afatinib (76).

The optimal treatment of patients with tumors that harbor EGFR mutations and ALK gene rearrangement who develop acquired resistance to EGFR and ALK tyrosine kinase inhibitors has yet to be defined. While most patients are managed with chemotherapy, the evidence to support this therapeutic approach is limited and the documented response rate with chemotherapy in patients with EGFR-resistance disease is 10-20\% (77). As more targeted therapies become available, a more informed approach to the treatment of acquired disease to targeted therapies may emerge through rebiopsy at the time of disease progression and tailoring of subsequent mechanism-based therapies.

Lung cancer is a heterogenous disease and resistance mechanisms to targeted molecular therapy are many. Given the multitude of signaling pathways and the evolving characteristics of resistant disease, an up-front combination therapy that simultaneously inhibits multiple resistance pathways is likely to yield better clinical outcomes. Personalized targeted therapy at the time of disease recurrence may further improve survival. Importantly, an aggressive front-line strategy and a tailored management approach in the case of resistant disease has been successfully employed in the management of other diseases, including HIV (78), which has now come to be considered a chronic disease. Whether advanced lung cancer may someday have a similar clinical outcome remains to be seen. To achieve this, attention must be directed at reducing the toxicity of combination therapies and greater efforts made to define the molecular basis of acquired resistance.

\section{REFERENCES}

1. Scagliotti GV, Parikh P, von Pawel J, Biesma B, Vansteenkiste J, Manegold C, et al. Phase III study comparing cisplatin plus gemcitabine with cisplatin plus pemetrexed in chemotherapy-naive patients with advanced-stage non-small-cell lung cancer. J Clin Oncol (2008) 26:3543-51. doi:10.1200/JCO.2007.15.0375

2. Schiller JH, Harrington D, Belani CP, Langer C, Sandler A, Krook J, et al. Comparison of four chemotherapy regimens for advanced non-small-cell lung cancer. N Engl J Med (2002) 346:92-8. doi:10.1056/NEJMoa011954

3. Zhou C, Wu YL, Chen G, Feng J, Liu XQ, Wang C, et al. Erlotinib versus chemotherapy as first-line treatment for patients with advanced EGFR mutation-positive non small-cell lung cancer (OPTIMAL, CTONG-0802): a multicenter, open-label, randomized, phase 3 study. Lancet Oncol (2011) 12:735-42. doi:10.1016/S1470-2045(11)70184-X

4. Rosell R, Carcereny E, Gervais R, Vergnenegre A, Massuti B, Felip E, et al. Erlotinib versus standard chemotherapy as first-line treatment for European patients with advanced EGFR mutation-positive non small-cell lung cancer (EURTAC): a multicentre, open-label, randomized phase 3 trial. Lancet Oncol (2012) 13:239-46. doi:10.1016/S1470-2045(11)70393-X

5. Sechler M, Cizmic AD, Avasarala S, Van Scoyk M, Brzezinski C, Kelley N, et al. Non-small-cell lung cancer: molecular targeted therapy and personalized medicine - drug resistance, mechanisms, and strategies. Pharmacogenom Personal Med (2013) 6:25-36. doi:10.2147/PGPM.S26058

6. Meert AP, Martin B, Verdebout JM, Noël S, Ninane V, Sculier JP. Is there a relationship between c-erbB-1 and c-erbB-2 amplification and protein expression in NSCLC? Lung Cancer (2005) 47:325-36. doi:10.1016/j.lungcan.2004.07.047

7. Zhu CQ, da CunhaSantos G, Ding K, Sakurada A, Cutz JC, Liu N, et al. Role of KRAS and EGFR as biomarkers of response to erlotinib in National Cancer Institute of Canada Clinical Trials Group Study BR 21. J Clin Oncol (2008) 26(26):4268-75. doi:10.1200/JCO.2007.14.8924

8. Hirsch FR, Varella-Garcia M, Bunn PAJr, Franklin WA, Dziadziuszko R, Thatcher $\mathrm{N}$, et al. Molecular predictors of outcome with gefitinib in a phase III placebocontrolled study in advanced non small cell lung cancer. J Clin Oncol (2006) 24(31):5034-42. doi:10.1200/JCO.2006.06.3958

9. Ellis PM, Verma S, Sehdev S, Younas J, Leighl N. Implementation of a national EGFR testing strategy in a publicly funded health system. J Thorac Oncol (2011) 6:4.199. doi:10.1097/JTO.0b013e31829f6a 43

10. Kosaka T, Yatabe Y, Endoh H, Kuwano H, Takahashi T, Mitsudomi T. Mutations of the epidermal growth factor receptor gene in lung cancer: biological and clinical implications. Cancer Res (2004) 64:8919-23. doi:10.1158/0008-5472.CAN04-2818

11. Shigematsu H, Lin L, Takahashi T, Nomura M, Suzuki M, Wistuba II, et al. Clinical and biological features associated with epidermal growth factor receptor gene mutations in lung cancers. J Natl Cancer Inst (2005) 98:339-46. doi:10.1093/jnci/dji055

12. Mok TS, Wu YL, Thongprasert S, Yang CH, Chu DT, Saijo N, et al. Gefitinib or carboplatin-paclitaxel in pulmonary adenocarcinoma. N Eng J Med (2009) 361:947-57. doi:10.1056/NEJMoa0810699

13. Mitsudomi T, Morita S, Yatabe Y, Negoro S, Okamoto I, Tsurutani J, et al. Gefitinib versus cisplatin plus docetaxel in patients with non-small-cell lung cancer harboring mutations of the epidermal growth factor receptor (WJTOG3405): an open label, randomised Phase 3 trial. Lancet Oncol (2009) 11:121-8. doi:10.1016/S1470-2045(09)70364-X

14. Pao G, Girard N. New driver mutations in non-small-cell lung cancer. Lancet Oncol (2011) 12(2):175-80. doi:10.1016/S1470-2045(10)70087-5

15. Kwak EL, Bang YJ, Camidge DR, Shaw AT, Solomon B, Maki RG, et al. Anaplastic lymphoma kinase inhibition in non-small cell lung cancer. NEJM (2010) 363:1693-703. doi:10.1056/NEJMoa 1006448

16. Gong Y, Yao E, Shen R, Goel A, Arcila M, Teruya-Feldstein J, et al. High expression levels of total IGF-1R and sensitivity of NSCLC cells in vitro to anti-IGF-IR antibody (R1507). PLoS One (2009) 4:e7273. doi:10.1371/journal.pone.0007273

17. Li H, Schmid-Bindert G, Wang D, Zhao Y, Yang X, Su B, et al. Blocking the PI3K/AKT and MEK/ERK signaling pathways can overcome gefitinib resistance in non-small cell lung cancer cell lines. Adv Med Sci (2011) 56:275-84. doi:10.2478/v10039-011-0043-x

18. Weickhardt A, Doebele R, Oton A, Lettieri J, Maxson D, Reynolds M, et al. A phase I/II study of erlotinib in combination with the anti-insulin-like growth factor-1 receptor monoclonal antibody IMC-A12 (cixutumumab) in patients with advanced non-small cell lung cancer. J Thorac Oncol (2012) 7:419-26. doi:10.1097/JTO.0b013e31823c5b11 
19. Ramalingam SS, Spigel DR, Chen D, Steins MB, Engelman JA, Schneider CP, et al. Randomized phase II study of erlotinib in combination with placebo or R1507, a monoclonal antibody to insulin-like growth factor-1 receptor, for advanced-stage non-small-cell lung cancer. J Clin Oncol (2011) 29:4574-80. doi:10.1200/JCO.2011.36.6799

20. Mir O, Blanchet B, Goldwasser F. Drug-induced effects on erlotinib metabolism. N Eng J Med (2011) 365:379-80. doi:10.1056/NEJMc1105083

21. Tebbutt N, Pedersen MW, Johns TG. Targeting the ERBB family in cancer: couples therapy. Nat Rev Cancer (2013) 13:663-73. doi:10.1038/nrc3559

22. Carpenter $G$. Receptors for epidermal growth factor and other polypeptide mitogens. Ann Rev Biochem (1987) 56:881-914. doi:10.1146/annurev.bi.56.070187. 004313

23. Ellis PM, Liu G, Millward M, Perrone F, Shepherd FA, Sun S, et al. NCIC-CTG BR 26: a phase III randomized, double-blind, placebo controlled trial of dacomitinib versus placebo in patients with advanced/metastatic non-small cell lung cancer (NSCLC) who received prior chemotherapy and a EGFR TKI (Abst 8036). 50th ASCO Annual Meeting. Chicago, IL (2014).

24. Miller VA, Hirsh V, Cadranel J, Chen YM, Park K, Kim SW, et al. Afatinib versus placebo for patients with advanced, metastatic non-small cell lung cancer after failure of erlotinib, gefitinib, or both, and one or two lines of chemotherapy (LUX-LUNG 1): a phase 2b/3 randomised trial. Lancet Oncol (2012) 13(5):528-38. doi:10.1016/S1470-2045(12)70087-6

25. Kawano O, Sasaki H, Endo K, Suzuki E, Haneda H, Yukiue H, et al. PIK3CA mutation status is Japanese lung cancer patients. Lung Cancer (2006) 54:209-15. doi:10.1016/j.lungcan.2006.07.006

26. Huang S, Hölzel M, Knijnenburg T, Schlicker A, Roepman P, McDermott U, et al. MED12 controls the response to multiple cancer drugs through regulation of TGF- $\beta$ receptor signaling. Cell (2012) 151(5):937-50. doi:10.1016/j.cell.2012. 10.035

27. Yano S, Yamada T, Takeuchi S, Tachibana K, Minami Y, Yatabe Y, et al. Hepatocyte growth factor expression in EGFR mutant lung cancer with intrinsic and acquired resistance to tyrosine kinase inhibitors in a Japanese cohort. $J$ Thorac Oncol (2011) 6:2011-7. doi:10.1097/JTO.0b013e31823ab0dd

28. Li Z, Zhou S, Zhang L, Su C, Hang J, Zhao Y, et al. BIM induction of apoptosis triggered by EGFR-sensitive and resistance cell lines of non-small cell lung cancer. Med Oncol (2011) 28(2):572-7. doi:10.1007/s12032-010-9470-y

29. Costa DB, Halmos B, Kumar A, Schumer ST, Huberman MS, Boggon TJ, et al. BIM mediates EGFR tyrosine kinase inhibitor-induced apoptosis in lung cancers with oncogenic EGFR mutations. PLoS Med (2007) 4:e315. doi:10.1371/ journal.pmed.0040315

30. Faber AC, Corcoran RB, Ebi H, Sequist LV, Waltman BA, Chung E, et al. BIM expression in treatment-naïve cancers predicts responsiveness to kinase inhibitors. Cancer Discovery (2011) 1:352-65. doi:10.1158/2159-8290.CD-110106

31. Costa C, Molina MA, Drozdowskyj A, Giménez-Capitán A, Bertran-Alamillo J, Karachaliou N, et al. The impact of EGFRT790 mutations and BIM mRNA expression on outcome in patients with EGFR-mutant NSCLC treated with erlotinib or chemotherapy in the randomized phase III EURTAC trial. Clin Cancer Res (2014) 20(7):2001-10. doi:10.1158/1078-0432.CCR-13-2233

32. Foo J, Chmielecki J, Pao W, Michor F. Effects of pharmacokinetic processes and varied dosing schedules on the dynamics of acquired resistance to erlotinib in EGFR-mutant lung cancer. J Thorac Oncol (2012) 7:1583-93. doi:10.1097/JTO. ob013e31826146ee

33. Hamilton M, Wolf JL, Rusk J, Beard SE, Clark GM, Witt K, et al. Effects of smoking on the pharmacokinetics of erlotinib. Clin Cancer Res (2006) 12:2166-71. doi:10.1158/1078-0432.CCR-05-2235

34. Chmielecki J, Foo J, Oxnard GR, Hutchinson K, Ohashi K, Somwar R, et al. Optimization of dosing for EGFR-mutant non-small cell lung cancer with evolutionary cancer modeling. Sci Transl Med (2011) 3:90ra59. doi:10.1126/scitranslmed. 3002356

35. Jackman D, Pao W, Riely GJ, Engelman JA, Kris MG, Jänne PA, et al. Clinical definition of acquired resistance to epidermal growth factor receptor tyrosine kinase inhibitors in non-small-cell lung cancer. J Clin Oncol (2010) 28:357-60. doi:10.1200/JCO.2009.24.7049

36. Watanabe S, Tanaka J, Ota T, Kondo R, Tanaka H, Kagamu H, et al. Clinical responses to EGFR-tyrosine kinase inhibitor retreatment in non small-cell lung cancer patients who benefited from prior effective gefitinib therapy: a retrospective analysis. BMC Cancer (2011) 11:1. doi:10.1186/1471-2407-11-1
37. Chaft JE, Oxnard GR, Sima CS, Kris MG, Miller VA, Riely GJ. Disease flare after tyrosine kinase inhibitor (TKI) discontinuation in patients with EGFR mutant lung cancer and acquired resistance. J Clin Oncol (2011) 29:A\#e18001. doi:10.1158/1078-0432.CCR-11-1468

38. Kosaka T, Yatabe Y, Endoh H, Yoshida K, Hida T, Tsuboi M, et al. Analysis of epidermal growth factor receptor gene mutation in patients with non-small cell lung cancer and acquired resistance to gefitinib. Clin Cancer Res (2006) 12:5764-9. doi:10.1158/1078-0432.CCR-06-0714

39. Yu HA, Arcila ME, Rekhtman N, Sima CS, Zakowski MF, Pao W, et al. Analysis of tumor specimens at the time of acquired resistance to EGFR-TKI therapy in 155 patients with EGFR-mutant lung cancers. Clin Cancer Res (2013) 19:2240-7. doi:10.1158/1078-0432.CCR-12-2246

40. Bell DW, Gore I, Okimoto RA, Godin-Heymann N, Sordella R, Mulloy R, et al. Inherited susceptibility to lung cancer may be associated with the T790M drug resistance mutation in EGFR. Nat Genet (2005) 37:1315-6. doi:10.1038/ ng1671

41. Ramalingam SS, Blackhall F, Krzakowski M, Barrios CH, Park K, Bover I, et al. Randomized Phase II study of dacomitinib (PF-00299804), and Irreversible PanHuman Epidermal Growth factor receptor inhibitor, versus erlotinib in patients with advanced non-small cell lung cancer. J Clin Oncol (2012) 30(27):3337-44. doi:10.1200/JCO.2011.40.9433

42. Reckamp KL, Giaconne G, Camidge DR. A phase 2 trial of dacomitinib (PF00299804) an oral, irreversible pan-HER (human epidermal growth factor receptor) inhibitor, in patients with advanced non-small cell lung cancer after failure of prior chemotherapy and erlotinib. Cancer (2014) 120(8):1145-54. doi:10.1002/cncr.28561

43. Schuler MH, Planchard D, Chih-Hsin J, Kim J-H, De Marinis F, Chen Y-M, et al. Interim analysis of afatinib monotherapy in patients with metastatic NSCLC progressing after chemotherapy and erlotinib/gefitinib (E/G) in a trial of afatinib plus paclitaxel versus investigator's choice chemotherapy following progression on afatinib monotherapy. J Clin Oncol (2012) 30(Suppl 15):Abst 7557.

44. Su KY, Chen HY, Li KC, Kuo ML, Yang JC, Chan WK, et al. Pretreatment epidermal growth factor receptor (EGFR) T790M mutation predicts shorter EGFR tyrosine kinase inhibitor response duration in patients with non-small cell lung cancer. J Clin Oncol (2012) 30:433-40. doi:10.1200/JCO.2011.38.3224

45. Rosell R, Molina MA, Costa C, Simonetti S, Gimenez-Capitan A, BertranAlamillo J, et al. Pretreatment EGFR T790M mutation and BRCA1 mRNA expression in erlotinib-treated advanced non-small-cell lung cancer patients with EGFR mutations. Clin Cancer Res (2011) 17:1160-8. doi:10.1158/10780432.CCR-10-2158

46. Sequist LV, Yang JC, Yamamoto N, O’Byrne K, Hirsh V, Mok T, et al. Phase III study of afatinib or cisplatin plus pemetrexed in patients with metastatic lung adenocarcinoma with EGFR mutations. J Clin Oncol (2013) 31(27):3327-34. doi:10.1200/JCO.2012.44.2806

47. Wu YL, Zhou C, Hu CP, Feng J, Lu S, Huang Y, et al. Afatinib versus cisplatin plus gemcitabine for first-line treatment of Asian patients with advanced non small cell lung cancer harbouring EGFR mutations (LUX-lung 6): an open-label, randomized phase 3 trial. Lancet Oncol (2014) 15(2):213-22. doi:10.1016/S1470-2045(13)70604-1

48. Bean J, Brennan C, Shih JY, Riely G, Viale A, Wang L, et al. MET amplification occurs with or without T790M mutations in EGFR mutant lung tumors with acquired resistance to gefitinib or erlotinib. Proc Natl Acad Sci U S A (2007) 104:20932-7. doi:10.1073/pnas.0710370104

49. Takezawa K, Pirazzoli V, Arcila ME, Nebhan CA, Song X, de Stanchina E, et al. HER2 amplification: a potential mechanism of acquired resistance to EGFR inhibition in EGFR-mutant lung cancers that lack the second site EGFR 790M mutation. Cancer Discovery (2012) 2:922-33. doi:10.1158/2159-8290.CD-12-0108

50. Takezawa K, Pirazzoli V, Arcila ME, Nebhan CA, Song X, de Stanchina E, et al. HER2 amplification: a potential mechanism of acquired resistance to EGFR inhibition in EGFR-mutant lung cancers that lack second-site EGFRT790M mutation. Cancer Discovery (2012) 2(10):922-33. doi:10.1158/2159-8290.CD12-0108

51. Sequist LV, Waltman BA, Dias-Santagata D, Digumarthy S, Turke AB, Fidias P, et al. Genotypic and Histological Evolution of Lung Cancers Acquiring Resistance to EGFR Inhibitors. Sci Transl Med (2011) 3:75ra26. doi:10.1126/ scitranslmed.3002003

52. Ohashi K, Sequist LV, Arcila ME, Moran T, Chmielecki J, Lin YL, et al. Lung cancers with acquired resistance to EGFR inhibitors occasionally harbor BRAF 
mutations but lack mutations in KRAS, NRAS or MEK1. Proc Natl Acad Sci US A (2012) 109:E2127-33. doi:10.1073/pnas.1203530109

53. Sos ML, Koker M, Weir BA, Heynck S, Rabinovsky R, Zander T, et al. PTEN loss contributes to erlotinib resistance in EGFR-mutant lung cancer by activation of AKT and EGFR. Cancer Res (2009) 69:3256-61. doi:10.1158/0008-5472.CAN08-4055

54. Viloria-Petit AM, Kerbel RS. Acquired resistance to EGFR inhibitors: mechanisms and prevention strategies. Int J Radiat Oncol Phys (2004) 58:914-26. doi:10.1016/j.ijrobp.2003.09.091

55. Tabernero J. The role of VEGF and EGFR inhibition: implications for combining anti-VEGF and anti-EGFR agents. Mol Cancer Res (2007) 5:203-20. doi:10.1158/1541-7786.MCR-06-0404

56. Ciardiello F, Bianco R, Damiano V, Fontanini G, Caputo R, Pomatico G, et al. Antiangiogenic and antitumor activity of anti-epidermal growth factor receptor C225 monoclonal antibody in combination with vascular endothelial growth factor anti-sense oligonucleotide in human GEO colon cancer cells. Clin Cancer Res (2000) 6:3739-47.

57. Jung YD, Mansfield PF, Akagi M, Takeda A, Liu W, Bucana CD, et al. Effects of combination anti-vascular endothelial growth factor receptor and antiepidermal growth factor receptor therapies on the growth of gastric cancer in a nude mouse model. Eur J Cancer (2002) 38:1133-40. doi:10.1016/S09598049(02)00013-8

58. Herbst RS, Johnson DH, Mininberg E, Carbone DP, Henderson T, Kim ES, et al. Phase I/II trial evaluating the anti-vascular endothelial growth factor monoclonal antibody bevacizumab in combination with the HER-1/epidermal growth factor receptor tyrosine kinase inhibitor erlotinib for patients with recurrent non-small cell lung cancer. J Clin Oncol (2005) 23:2544-55.

59. Herbst RS, O’Neill VJ, Fehrenbacher L, Belani CP, Bonomi PD, Hart L, et al. Phase II study of efficacy and safety of bevacizumab in combination with chemotherapy or erlotinib compared with chemotherapy alone for treatment of recurrent or refractory non small cell lung cancer. J Clin Oncol (2007) 25:4743-50. doi:10.1200/JCO.2007.12.3026

60. Lee JS, Hirsh V, Park K, Qin S, Blajman CR, Perng RP, et al. Vandetanib versus placebo in patients with advanced non-small cell lung cancer after prior therapy with an epidermal growth factor tyrosine kinase inhibitor: a randomized, double-blind phase III trial (ZEPHYR). J Clin Oncol (2012) 30(1):1114-21. doi:10.1200/JCO.2011.36.1709

61. Arcila ME, Oxnard GR, Nafa K, Riely GJ, Solomon SB, Zakowski MF, et al. Rebiopsy of lung cancer patients with acquired resistance to EGFR inhibitors and enhanced detection of the T790M mutation using a locked nucleic acid-based assay. Clin Cancer Res (2011) 17:1169-80. doi:10.1158/1078-0432.CCR-10-2277

62. Uramoto H, Iwata T, Onitsuka T, Shimokawa H, Hanagiri T, Oyama T. Epithelialmesenchymal transition in EGFR-TKI acquired resistant lung adenocarcinoma. Anticancer Res (2010) 30:2513-7.

63. Suda K, Murakami I, Katayama T, Tomizawa K, Osada H, Sekido Y, et al. Reciprocal and complementary role of MET amplification and EGFR T790M mutation in acquired resistance to kinase inhibitors in lung cancer. Clin Cancer Res (2010) 16:5489-98. doi:10.1158/1078-0432.CCR-10-1371

64. Perner S, Wagner PL, Demichelis F, Mehra R, Lafargue CJ, Moss BJ, et al. EML4ALK fusion lung cancer: a rare acquired event. Neoplasia (2008) 10:298-302.

65. Pan Y, Zhang Y, Li Y, Hu H, Wang L, Li H, et al. ALK, ROS1 and RET fusions in 1139 lung adenocarcinomas: a comprehensive study of common and fusion pattern-specific clinicopathologic, histologic and cytologic features. Lung Cancer (2014) 84(2):121-6. doi:10.1016/j.lungcan.2014.02.007

66. Soda M, Choi YL, Enomoto M, Takada S, Yamashita Y, Ishikawa S, et al. Identification of the transforming EML4-ALK fusion gene in non-small-cell lung cancer. Nature (2007) 448:561-6. doi:10.1038/nature05945

67. Shaw AT, Kim DW, Nakagawa K, Seto T, Crinó L, Ahn MJ, et al. Crizotinib versus chemotherapy in advanced ALK-positive lung cancer. N Eng J Med (2013) 368(25):2385-94. doi:10.1056/NEJMoa1214886
68. Zhang S, Wang F, Keats J, Zhu X, Ning Y, Wardwell SD, et al. Crizotinib-resistant mutants of EML4-ALK identified through an accelerated mutagenesis screen. Chem Biol Drug Des (2011) 78(6):999-1005. doi:10.1111/j.1747-0285.2011. 01239.x

69. Gainor JF, Varghese AM, Ou SH, Kabraji S, Awad MM, Katayama R, et al. ALK rearrangements are mutually exclusive with mutations in EGFR or KRAS: an analysis of 1,683 patients with non-small cell lung cancer. Clin Cancer Res (2013) 19:4273-81. doi:10.1158/1078-0432.CCR-13-0318

70. Choi YL, Soda M, Yamashita Y, Ueno T, Takashima J, Nakajima T, et al. ELM4ALK mutations in lung cancer that confer resistance to ALK inhibitors. N Eng J Med (2010) 363:1734-9. doi:10.1056/NEJMoa1007478

71. Shaw AT, Mehra R, Kim DW, Felip E, Chow LQM, Camidge DR, et al. Clinical activity of the ALK inhibitor LDK378 in advanced ALK-positive NSCLC. J Clin Oncol (2013) 31(Suppl):Abst8010.

72. Ohashi K, Maruvka YE, Michor R, Pao W. Epidermal growth factor receptor tyrosine kinase inhibitor-resistant disease. J Clin Oncol (2013) 31:1070-80. doi:10.1200/JCO.2012.43.3912

73. Nishie K, Kawaguchi T, Tamiya A, Mimori T, Takeuchi N, Matsuda Y, et al. Epidermal growth factor receptor tyrosine kinase inhibitors beyond progressive disease: a retrospective analysis for Japanese patients with activating EGFR mutations. J Thoracic Oncol (2012) 7(11):1722-7. doi:10.1097/JTO. 0b013e31826913f7

74. Asami K, Okuma T, Hirashima T, Kawahara M, Atagi S, Kawaguchi T, et al. Continued treatment with gefitinib beyond progressive disease benefits patients with activating EGFR mutations. Lung Cancer (2013) 79(3):276-82. doi:10.1016/j. lungcancer.2012.11.022

75. Yu HA, Sima CS, Huang J, Solomon SB, Rimner A, Paik P, et al. Local therapy with continued EGFR tyrosine kinase inhibitor therapy as a treatment strategy in EGFR-mutant advanced lung cancers that have developed acquired resistance to EGFR tyrosine kinase inhibitors. J Thorac Oncol (2013) 8(3):346-51. doi:10.1097/JTO.0b013e31827e1f83

76. Schuler MH, Yang CH, Park K, et al. Continuation of afatinib beyond progression: results of a randomized, open label, phase III trial of afatinib plus paclitaxel (P) versus investigator's choice chemotherapy (CT) in patients (pts) with metastatic non-small cell lung cancer (NSCLC) progressed on erlotinib/gefitinib (E/G) and afatinib - LUXLUNG-5 (LL5) (Abst 8019). 50th ASCO Annual Meeting. Chicago, IL (2014).

77. Gridelli C, Cardiello F, Gallo C, Feld R, Butts C, Gebbia V, et al. First-line erlotinib followed by second-line cisplatin-gemcitabine chemotherapy in advanced nonsmall cell lung cancer: the TORCH randomized trial. J Clin Oncol (2012) 30:3002-11. doi:10.1200/JCO.2011.41.2056

78. Bock C, Lengauer T. Managing drug resistance in cancer: lessons from HIV therapy. Nat Rev Cancer (2012) 12:494-501. doi:10.1038/nrc3297

Conflict of Interest Statement: The authors declare that the research was conducted in the absence of any commercial or financial relationships that could be construed as a potential conflict of interest.

Received: 26 May 2014; accepted: 07 July 2014; published online: 23 July 2014. Citation: Spaans JN and Goss GD (2014) Drug resistance to molecular targeted therapy and its consequences for treatment decisions in non-small-cell lung cancer. Front. Oncol. 4:190. doi: 10.3389/fonc.2014.00190

This article was submitted to Thoracic Oncology, a section of the journal Frontiers in Oncology.

Copyright (C) 2014 Spaans and Goss. This is an open-access article distributed under the terms of the Creative Commons Attribution License (CC BY). The use, distribution or reproduction in other forums is permitted, provided the original author(s) or licensor are credited and that the original publication in this journal is cited, in accordance with accepted academic practice. No use, distribution or reproduction is permitted which does not comply with these terms. 